\title{
Institucionalização e a configuração atual da Formação em Museologia no Brasil
}

\section{Luciana Ferreira da Costa ${ }^{I}$}

http://orcid.org/0000-0002-5894-2741

${ }^{I}$ Universidade Federal da Paraíba, PB, Brasil.

Doutora em História e Filosofia da Ciência pela Universidade de Évora, Portugal. Professora do Departamento de Ciência da Informação

http://dx.doi.org/10.1590/1981-5344/3748

Este relato tem como objetivo abordar a institucionalização e a configuração atual da formação em Museologia no Brasil, tendo como ponto de partida sua origem em 1932 até seu estado atual neste século XXI. Metodologicamente, baseia-se em pesquisa de cariz bibliográfico, documental e descritiva, pautado em fontes históricas primárias e secundárias, sob análise qualitativa. Relata a formação a partir da criação do Curso de Museus do Museu Histórico Nacional, sua evolução para os cursos de graduação e, consequente, pós-graduação em Museologia, culminando nos atuais 17 cursos de graduação e seis programas de pós-graduação stricto sensu. Conclui que a formação em Museologia no Brasil é marcada por pioneirismo iniciado quando da criação do Museu Histórico Nacional em 1922 e considerável avanço, sobretudo, nos primeiros anos do século XXI. Contudo, o cenário atual de formação ainda não atinge todas as regiões do país, visto que os cursos de pós-graduação stricto sensu estão presentes em três das cinco regiões do Brasil. 
Palavras-Chave: Museologia; Formação; Curso de Graduação; Curso de pós-graduação; Brasil.

\section{Institucionalization and the current configuration of formation in Museology from Brasil}

This paper describes the historical course of the formation in Museology from Brazil, from its origins in the 1930s to the present moment of the 21st century. As a historical research report, the methodology was based on a bibliographical, documentary and describe work, based on primary and secondary historical sources, with a qualitative analysis, describing the history of the training in Museology in Brazil, not leaving aside people and institutions involved in this process. It reports on the formation in Museology in Brazil from the creation of the Museum Course of the National Historical Museum, its evolution for the undergraduate and postgraduate courses in Museology, culminating in the current 17 undergraduate courses and six stricto sensu graduate programs. It concludes that the training in Museology in Brazil was marked by a pioneering beginning in the 1930 s and progress, especially in the first years of the 21st century. However, the current training offer still does not fully meet the needs of the country, as there is a significant discrepancy between the number of undergraduate courses in all regions of the country and the number of stricto sensu graduate programs with restricted offer, to date, to only three regions of the country.

Keywords: Museology; Formation; Undergraduate and postgraduate courses in Museology; Brazil. 


\section{Reflexões preliminares}

O início da formação em Museologia é marcado pelas disposições da École du Louvre em Paris e do Pensylvânia Museum da Filadélfia, instituições que datam, respectivamente, de 1882 e 1908. Na École du Louvre "imparten enseñanzas de historia del art y de museologia"(HERNÁNDEZ-HERNÁNDEZ, 2006, p. 18). Particularmente, o curso ofertado pela École du Louvre, em 1927, é considerado "como o primeiro curso da França a qualificar e formar conservadores para os museus do país". Isto fez com que o com que o referido ano ficasse conhecido, na França, como "o ano da Museologia"(SCHEINER, 2009, p. 138).

Mesmo assim, a literatura registra que, desde 1921, a Universidade de Masaryk em Brno na República Tcheca já ofertava uma cátedra em Museologia com o objetivo de formar o pessoal técnico que atuava nos museus checos e eslovacos (MAROEVIĆ, 1998).

Em termos do continente americano,o início da formação em Museologia é atribuído aoFogg Art Museum em Harvard com origem no ano de 1923 (MAROEVIĆ, 1998).

Às disposições formativas supracitadas, acrescenta-se a iniciativa do Brasil com a criação do Curso de Museus do Museu Histórico Nacional (MHN)em 1932 (SCHEINER, 2009), o qual teve sua inauguração noticiada nos jornais da época com grande repercussão ${ }^{1}$ (COSTA, 2017). Alude afirmar que o recém-criado Curso de Museus no Brasil tinha, em sua origem, a responsabilidade de alargar o diálogo entre o país e as reflexões internacionais (BRULON SOARES; CARVALHO; CRUZ, 2014).

Na perspectiva de Tereza Scheiner, "a partir dessas experiências [de formação], a Museologia torna-se gradualmente reconhecida como um campo do conhecimento, com identidade própria - e evolui em direção à estrutura interdisciplinar"(SCHEINER, 2015, p. 40).

Com a crescente oferta de cursos em Museologia, sobretudo a partir do século XX nos mais diversos lugares do mundo (POULOT, 2013), inclusive no Brasil, o percurso histórico e social reflete que a formação em Museologia se institucionalizou, seguindo o seu desenvolvimento e sua consolidação como disciplina científica, sendo devidamente contemplada no contexto universitário passando, portanto, indiscutivelmente "a deter um estatuto científico" (BRIGOLA, 2013, online).

A partir destas reflexões preliminares, o presente relato abordaa institucionalização e a configuração atual da formação em Museologia no

\footnotetext{
${ }^{1}$ Hemeroteca da Biblioteca Nacional.Disponível em: http://memoria.bn.br/DocReader/DocReader.aspx?bib=221961_01\&PagFis=10878\&Pesq=Curso\%20 Univers it\% C3\% A1rio. Acesso em: 11 dez. 2015.
} 
Brasil, tendo como ponto de partida sua origem em 1932 até seu estado atual neste século $\mathrm{XXI}^{2}$.

Espera-se que o estado da formação aqui exposto se revele contributivo para as reflexões de uma Museologia brasileira detentora de interesse pelas questões particulares do país continental que a abriga e, especialmente, em compasso com questões de impacto global - a exemplo da pandemia de COVID-19.

\section{Institucionalização da formação em Museologia}

A história da formação em Museologia no Brasil começou com a institucionalização do Curso de Museus em 1932 pelo MHN, museu este criado dez anos antes, em 1922.

A idealização do referido curso, criado pelo Decreto-Lei no 21.129 de 07 de março de 1932, deu-se com a finalidade de formar os profissionais do MHN, do Arquivo Nacional e da Biblioteca Nacional pela oferta de um curso técnico de tronco comum (COSTA, 2017).

O Curso de Museus funcionou sob responsabilidade e fiscalização da diretoria interina do $\mathrm{MHN}$, na pessoa do historiador Rodolfo Augusto Garcia Amorim (1873-1949) que dirigiu o museu entre os anos de 1930 e 1932. Durante o referido período Gustavo Barroso, idealizador do Curso de Museus, havia sido destituído do cargo devido às transformações políticas provocadas pela ascensão de Getúlio Vargas à Presidência. Mais tarde, ainda em 1932, contando com a simpatia do Presidente Getúlio Vargas, com quem já tinha uma estreita relação desde a participação dos dois na Conferência de Paz de Versailles em 1919, Gustavo Barroso foi restituído ao cargo de diretor do Museu (que ocupou até o ano de seu falecimento em 1959) e de coordenador do curso (ABREU, 1995; WILLIAMS, 1997).

O curso tinha como formadores os funcionários do próprio $\mathrm{MHN}^{3}$ que, de acordo com o Decreto de criação do Curso de Museus, foram "designados por portaria do diretor do Museu Histórico Nacional, entre os funcionários da mesma repartição"(SOPHIA; LOUREIRO, 2012; TANUS, 2013). Inclusive, por ocasião de solicitação de reforma do Curso, sob a direção de Gustavo Barroso há uma década, este fez questão de destacar

\footnotetext{
${ }^{2}$ Trata-se de um recorte da investigação de doutoramento da autora, contudo, consiste de versão revisitada e atualizada.

${ }^{3} \mathrm{O}$ quadro de docentes do curso era formado estritamente por homens e, em sua maioria, com origem na região Nordeste do Brasil: o cearense Gustavo Barroso (Diretor); o potiguar Rodolfo Garcia (Diretor); o baiano Pedro Calmon (Secretário do MHN); o carioca, criado na Bahia, Joaquim Menezes de Oliva (Chefe da $1^{\text {a }}$ Seção); o potiguar João Angyone Costa (30 Oficial); e o carioca Edgar de Araújo Romero (Chefe da $2^{\circ}$ Seção) (SÁ, 2007).
} 
que o curso funcionava "com a cooperação de funcionários que são professôres (sic), sem nenhum provento material a lhes recompensar o esforço durante todo este tempo" (BARROSO, 1944, p. 191).

Os primeiros "museólogos" do país, segundo Ivan Coelho de Sá (2007), chamados na época de Conservadores de Museus se formaram em 1933.

Entre os anos de 1932 a 1944, o curso tinha duração de dois anos e apresentava um perfil estritamente técnico. Sobre discussões que apontam o curso como de natureza estritamente técnica, Sá explica que, considerando a sua criação em uma instituição cultural, esta é uma característica totalmente aceitável. Porém, na visão do autor, em termos legais, o curso já apresentava requisitos de curso superior, pois exigia dos candidatos a conclusão do então chamado ensino secundário (SÁ, 2014), atualmente considerado ensino médio.

A criação do curso em uma instituição museológica se deu para atender os propósitos do MHN em sua demanda por profissionais com formação especializada para atuar na instituição, mas também se deu com a partir das ideias e correntes de pensamento sobre os museus as quais foram propagadas principalmente pela criação do Office International des Musées (OIM), uma organização destinada à sistematizar informações sobre museus de todo o mundo(BRULON-SOARES; CARVALHO; CRUZ, 2014).

O Decreto de criação do curso, já referido, previa o ensino das disciplinas dividido em dois anos: no primeiro ano História Política do Brasil (referente ao período colonial), Numismática (referente à parte geral), História da Arte (especialmente do Brasil), Arqueologia aplicada ao Brasil, e, no segundo ano, História Política e Administrativa do Brasil, Numismática (brasileira), Sigilografia, Epigrafia, Cronologia e Técnica de Museus. Na época, quem concluía o curso era chamado de 'Conservador de museus', termo traduzido do francês (BRASIL, 1932).

Em 1944 foi aprovado o Regulamento do Curso de Museus por meio do Decreto no 16.078 de 13 de julho de 1944. O referido Decreto tinha por finalidade: a) preparar pessoal habilitado a exercer as funções de conservador de museus históricos e artísticos ou de instituições análogas; b) transmitir conhecimentos especializados sobre assuntos históricos e artísticos, ligados às atividades dos museus mantidos pelo Governo Federal; e c) incentivar o interesse pelo estudo da História do Brasil e da arte nacional (Brasil, 1944).

O Regulamento do Curso de Museus estabelecia a duração de três anos letivos, divididos em duas partes (parte geral e parte especial) ${ }^{4} \mathrm{o}$

$\begin{array}{lccccc}{ }^{4} \text { Conforme } & \text { consulta } & \text { a } & \text { Decreto } & \text { disponível } \\ \text { http://www2.camara. leg.br/legin/fed/decret/1940-1949/decreto-16078-13-julho-1944- }\end{array}$ 
que possibilitou ao mesmo adquirir perfil de curso superior, com o objetivo de capacitar recursos humanos para o exercício da função de conservador de museus históricos e artísticos ou instituições com finalidades análogas. Exigências que foram atendidas pelo Museu Histórico Nacional na promoção do seu curso superior.

Com o regulamento e a nova estrutura curricular, o quadro de docentes foi renovado. A primeira geração de docentes, egressa do Curso de Museus, substituiu os primeiros docentes do curso. A esta geração assenta o título de "primeira geração" de uma Museologia não mais autodidata (SÁ, 2007; 2019), pois pôde contar, além da sua intuição, com uma formação estruturada que a muniu das bases teóricas essenciais para tal exercício 5 .

Houve, também, no Regulamento do Curso de Museus a institucionalização das bolsas de estudos que começaram a ser concedidas em caráter experimental em 1942. No período de "1942 a 1967 foram concedidas 64 bolsas de estudos aos estados ${ }^{6}$, das quais 15 alunos não chegaram a concluir o Curso (...)" (SIQUEIRA, 2009, p. 35).

Desde a sua institucionalização e desenvolvimento, é fato que o Curso de Museus é marcado pela característica pessoal de Gustavo Barroso, seu idealizador, visto como "um personagem emblemático conhecido pela valorização do culto a saudade e preocupado com a construção de uma história nacional brasileira na forma de continuidade da tradição imperial" (DUARTE CÂNDIDO; RUOSO, 2012, p. 36).

$\mathrm{Na}$ perspectiva de Siqueira o estilo barrosiano de ensino "refere-se à forma de dirigir, ensinar e transmitir conhecimentos e conceitos, bem como as normas e técnicas empregadas e aplicadas pelo seu fundador" (SIQUEIRA, 2009, p. 26). A autora cita como exemplo a adoção, por um longo período de tempo, da obra de Barroso, considerada compêndio dos

461459-publicacaooriginal-1-pe.html: consta que a parte Geral compreendia duas séries comuns a todos os alunos. Já a parte Especial englobava uma série para cada uma das seguintes seções: a) Museus Históricos; e b) Museus de Belas Artes ou Artísticos.

${ }^{5}$ Assumiram a docência em 1945: José Francisco Félix de Mariz (Pintura e Gravura); Anna Barrafatto (Escultura e História da Arte); Oswaldo Mello Braga de Oliveira (História da Arte Brasileira); Jenny Dreyfus (Sigilografia e Filatelia); Diógenes Vianna Guerra (Etnografia, Arqueologia, Arte Indígena e Arte Popular); e Mario Antonio Barata (Artes Menores). A partir de 1947, Nair Moraes de Carvalho, começa a ministrar a disciplina Escultura (SIQUEIRA, 2009, p. 31-32).

${ }^{6}$ Do total de 64 bolsas distribuídas durante 25 anos, ou seja, de 1942 até 1967, quando foram extintas, o estado da Bahia somou com 15 bolsistas; seguido pelo Ceará com 8; Rio Grande do Sul, 7; São Paulo, Minas Gerais e Maranhão com 6; Paraná com 3; Amazonas, Pernambuco, Rio de Janeiro e Santa Catarina, com 2; e enfim Espírito Santo, Goiás, Mato Grosso e Sergipe com apenas uma bolsa. Houve, também, uma bolsa destinada à Argentina. 
seus conhecimentos e aulas, obrigatória para profissionais da área de museus, "que resume tanto o currículo quanto o conceito do curso, Introdução à Técnica de Museus, publicado em dois volumes, (o primeiro volume em 1946 e o segundo em 1947)". O primeiro volume foi dedicado ao processamento técnico de acervo e o segundo às coleções (SIQUEIRA, 2009, p. 27).

Em rigor, o livro Introdução à Técnica de Museus (BARROSO, 1946, 1947), publicado em dois volumes, volume I (Parte geral e Parte básica) ${ }^{7}$ e volume II (parte especializada) ${ }^{8}$, foi a primeira obra de referência da Museologia brasileira "e se destinava a servir ao ensino superior para a formação de profissionais de museus. Seu enfoque, tal como o título expressa, estava no conjunto de regras e princípios da organização de museus e tratamento de suas coleções de objetos" (KNAUSS, 2011, p. 585). A obra foi elaborada "a partir da experiência [de Barroso] enquanto professor do curso, de suas leituras e de suas pesquisas" (SILVA, 2014, p. 185). Na obra, em que o próprio Barroso ressalta o ineditismo do assunto no país, são explicitadas as fontes textuais utilizadas (artigos em revistas internacionais), sendo a fonte mais importante o livro Muséographie: Architecture et Aménnagement des Musées d'Art publicado em 1935, em dois volumes, com origem na Conferência Internacional de Madrid realizada em 1934 (SÁ, 2007; 2013). Entende-se, nesse contexto, que o livro Introdução à Técnica de Museus se constitui documento histórico para a área da Museologia no Brasil, o qual motivou estudos importantes (SILVA, 2014).

Outro estudo que se dedicou a investigar a contribuição de Gustavo Barroso para o MHN e, consequentemente, para a área da Museologia no Brasil, foi o de Mario Chagas (2003) que abordou os indícios que levaram Barroso a idealizar o MHN e o Curso de Museus, além da sua relação com a disciplina que considerava essencial na formação dos ingressos no curso, a já referida Introdução à Técnica de Museus. E não há como deixar de evidenciar os estudos de Sá e, sobretudo, sua última obra, lançada em

7 Contempla noções de organização, arrumação, catalogação e restauração; de cronologia, epigrafia, bibliografia, diplomática e iconografia. Disponível em: http://doc virt.com/docreader.net/DocReader. aspx?bib =MHN\&PagFis $=11190 \& P e s q=G$ ustav.

8 Contempla noções de heráldica, bandeiras, condecorações, armaria, arte naval, viaturas, arquiteturas, indumentária, mobiliário, cerâmica e cristais, joalharia, prataria, bronzes artísticos, mecanismos, instrumentos, de suplício e arte religiosa. Disponível em: http://docvirt.com/docreader. net/DocReader. aspx?bib =MHN\&PagFis $=11190 \& P e s q=G$ ustav. 
2019, Matrizes do Pensamento Museológico de Gustavo Barroso que percorre o caminho trilhado por Barroso ao escrever sua obra didática.

Outra questão que reflete o estilo de Barroso e a atuação dos primeiros docentes do curso foi a criação do periódico Anais do MHN em 1940. A criação do periódico cogita "o efetivo controle do que se ensinava e transmitia aos alunos do curso, bem como as linhas de pensamento a serem seguidas e trabalhadas naquela instituição" (SIQUEIRA, 2009, p. 27).

A consolidação do estilo de Barroso encontrou continuidade por meio dos seus alunos pioneiros, dos quais alguns se tornaram docentes do Curso e outros que reforçam o estilo do idealizador em diversas instituições museais do país, sobretudo, no tocante à museografia, conservação e documentação (RANGEL, 2012; SÁ, 2019).

A análise da atuação dos egressos do Curso de Museus no mercado de trabalho nas décadas de 1930,1940,1950, 1960 e 1970 do século XX foi investigada por Siqueira (2009). Em seu estudo, apresenta o perfil profissional do egresso formado pelo Curso de Museus. Por sua vez, a investigação de Silva (2014) traz entrevistas realizadas com ex-alunos do Curso de Museus com vistas ao conhecimento de suas memórias no tocante ao curso de que são egressos e à sua experiência de convivência e trabalho no MHN.Em outro víeis, o estudo de Coelho (2015) analisou o pensamento museológico brasileiro desde 1932 à 1985, evidenciando o pioneirismo do Curso de Museus na institucionalização do campo e na cientifização das práticas museológicas.

O Curso de Museus, por meio de convênio firmado entre o MHN e a Universidade do Brasil ${ }^{9}$, atual Universidade Federal do Rio de Janeiro (UFRJ), em 12 de julho de 1951, passou de seu status técnico para status universitário. $O$ então adquirido mandato universitário exigiu a reorganização do curso e de sua estrutura administrativa, "sendo criados o Conselho Departamental e os Departamentos de Técnica de Museus, de História do Brasil, de História da Arte e de Antropologia" (SÁ, 2007, p. 30). Durante a gestão do então Diretor do MHN Léo Fonseca e Silva que se deu no período de 1967 a 1970, houve empenho por parte do mesmo para alterar a nomenclatura do curso para Faculdade de Museologia, tendo encaminhado proposta para a Câmara de Planejamento do Conselho Federal de Educação, o que foi negado sob a alegação de que o curso era vinculado à uma instituição de cultura e não a uma universidade (BRULON-SOARES; CARVALHO; CRUZ, 2014).O Curso assumiu a designação informal de Escola Superior de Museologia (ESM), alterando-se sua duração, em 1974, de três para quatro anos em 1974.

\footnotetext{
${ }^{9}$ Pedro Calmom, que proferiu a aula magna do Curso de Museus e compunha o quadro de professores do mesmo, era o então Reitor desta Universidade (SÁ, 2007).
} 
A efetiva mudança física e conceitual do Curso de Museus ocorreu apenas quando foi transferido, em 1979, para a então Federação das Escolas Federais Isoladas do Rio de Janeiro (FEFIERJ) ${ }^{10}$, atual Universidade Federal do Estado do Rio de Janeiro (UNIRIO). Esta situaçãorepresentou o rompimento com o modelo de Barroso até então estabelecido (RANGEL, 2012) e reverberou, após a transferência, na mudança de nomenclatura, de Curso de Museus para Curso de Graduação em Museologia (TANUS, 2013).

A década de 1970 é encarada como decisiva para o Curso de Museus, visto ter sido neste período que o curso enfrentou expressivas mudanças conceituais, em seus objetivos, adaptações na matriz curricular ${ }^{11}$, ampliação das turmas, dentre outras, especialmente, por sua incursão no contexto universitário.

\section{A trajetória e a configuração atual da formação em Museologia: os cursos de graduação e de pós-graduação no Brasil}

Após a institucionalização do Curso de Museus, em 1932, discutida na seção anterior, é que a formação em Museologia no Brasil viu nascer o segundo curso na área. Trata-sedo Curso de Graduação em Museologia da Universidade Federal da Bahia (UFBA), criado em $1969^{12}$.

O referido curso tem sua história marcada por momentos de adversidades e conquistas. O curso enfrentou adversidades, conforme destaca Heloísa Helena Costa, desde a sua gestão acadêmica e administrativa, "tamanhas foram as divergências quanto a então recémchegada 'disciplina científica', não aceita pelos demais professores, à época (anos 70-80)" (COSTA, 2009, p. 238).

A autora relata a história significativa do curso de Museologia da UFBA, evidenciando alguns fatos: como as disciplinas consideradas técnicas - Técnicas de Museus I e Técnicas de Museus II - terem sido ministradas por um recém-formado do Curso de Museus do MHNpor falta

\footnotetext{
${ }^{10}$ Até 1977, mesmo incorporado à Federação das Escolas Federais Isoladas do Rio de Janeiro (FEFIERJ), o Curso continuava a funcionar nas dependências do MHN.

11 Conforme Brulon-Soares, Carvalho e Cruz (2014), dada a reformulação do Regimento aprovado em 1974 pelo Conselho Federal de Educação, a antiga divisão curricular por habilitações de Museus Históricos, Artísticos, Científicos e Escolares Polivalentes é descartada, passando a vigorar uma formação integrada, com atividades obrigatórias de estágios e organizações de exposições.

12 Instalado na Faculdade de Filosofia e Ciências Humanas (FFCH) com vinculação ao Departamento de História, idealizado pelo Arqueólogo e Historiador de Arte espanhol Valentin Rafael Simón Joaquín Calderón de La Vara, que coordenou o referido curso (COSTA, 2009).
} 
de docentes formados na área no curso ofertado pela UFBA e, também, comenta o período de bloqueio do curso em 1974, mas que anos depois foi reconhecido pelo Conselho Federal de Educação por meio do Decreto 83.327 de 16 de abril de 1979 .

A criação do Curso de Museologia da UFBA representou, segundo Waldisa Rússio (2010, p. 228), "a vitória de um grupo unido e consciente de professores e alunos, mas também assinala a adoção inovadora de um currículo voltado para a realidade social e regional".

Em 1975, no âmbito de uma instituição de ensino superior privado, deu-se a criação do Curso de Graduação em Museologia da Faculdade de Arqueologia e Museologia Marechal Rondon (FAMARO), no Rio de Janeiro, o qual foi transferido em 1978 para Faculdades Integradas Estácio de Sá (FINES) (TANUS, 2013).O curso se encerrou em 1995, sendo o seu alunado absorvido pela UNIRIO.

Dessa forma, desde a década de 1940 até o início do século XXI a formação superior em Museologia no Brasil contou apenas com os cursos do Rio de Janeiro e da Bahia, contou com cursos de especialização organizados em alguns estados do país, e, também, com cursos de extensão e eventos que procuravam amenizar os gaps e atender as demandas (DUARTE CÂNDIDO, 2013). Assim, "a formação profissional para os museus brasileiros registra trajetória não linear, mas com momentos significativos com esforços de muitas gerações de técnicos e professores (...) permeada por utopias e conquistas sistemáticas" (BRUNO, 2015, p. 104-105).

Uma destas conquistas foi, em termos de formação especializada, a criação do primeiro Curso de Pós-Graduação Lato Sensu em Museologia no ano de 1977, em São Paulo, sob a idealização de Waldisa Rússio. A criação do curso em nível de pós-graduação, segundo sua idealizadora, além do seu viés interdisciplinar, estava ancorada em questões institucional, motivacional e regulatória, onde "a primeira diz respeito à instituição em que foi instalado o curso; a segunda (...) diz respeito ao momento em que surgiu o curso; e a terceira (...) tem a ver com novos regulamentos expedidos pelo Ministério da Educação" (RÚSSIO, 2010, p. 234).

No tocante à primeira questão, Waldisa Rússio chama a atenção para o fato de o curso ter surgido junto à Escola Pós-Graduada de Ciências Sociais, considerada pela autora como "vanguardeira na formação de pesquisadores e cientistas sociais", possibilitou ao mesmo se apoiar em "sua estrutura e forma pedagógica", já que seguiu o percurso da referida Escola. A autora pontua, ainda, consequentemente, a "multiprofissionalidade como essencial ao desenvolvimento do programa pedagógico, mas também a interdisciplinaridade como método" (RÚSSIO, 2010, p. 232). 
A criação do curso foi motivada pela Resolução no 14 de 1977 do Conselho Federal de Educação (CFE), como uma ação do então Ministério da Educação e Cultura que neste mesmo ano impedia a abertura de novos cursos de graduação em Museologia, dado que o curso da UFBA se encontrava em vias de fechamento devido à sua estagnação, o que não ocorreu graças à "solitária e solidária atitude do Professor Mario Barata [egresso do Curso de Museus], que enviou carta ao Reitor daquela instituição, manifestando-se contra o fechamento do curso. Já que faltavam outras vozes solidárias, que se ouvisse ao menos uma solitária" (RÚSSIO, 2010, p. 236).

Waldisa Rússio viu na Resolução supracitada um instrumento que proporcionava por um lado a criação de curso de especialização e, por outro, a possibilidade de criação, consequentemente, de um Mestrado no âmbito da Escola Pós-Graduada de Ciências Sociais (RÚSSIO, 2010, p. 236).

O curso foi criado dentro da Fundação Escola de Sociologia e Política do Estado de São Paulo (FESPSP), concebido com duração de três anos conforme recomendação do Conselho Internacional de Museus (ICOM), no entanto durante dois anos o curso funcionou no Museu de Arte de São Paulo Assis Chateaubriand (MASP). Após este período passou a funcionar de fato na FESPSP, o que se deu até o ano de 1992. A importância do curso para a área da Museologia é inegável, visto que "o curso e, posteriormente, o Instituto de Museologia da FESPSP, foram responsáveis pela formação de toda uma geração de museólogos com expressiva atuação no país" (SANTOS, 2008, p, 192).

É importante destacar a existência do Curso de Especialização em Museologia do Museu de Arqueologia e Etnologia (MAE) da Universidade de São Paulo (USP), que funcionou no período de 1999 a 2006, com quatro edições (DUARTE CÂNDIDO; RUOSO, 2012), e também as iniciativas pontuais do Museu de Arte de São Paulo Assis Chateaubriand (MASP) e da Pontifícia Universidade Católica do Rio Grande do Sul (PUCRS), ambos com cursos desativados. Para além destes, destacam-se, ainda, diversos outros cursos a saber: o Curso de Especialização em Museologia, Colecionismo e Curadoria do Centro Universitário de Belas Artes em São Paulo criado em 2013, o Curso de Especialização em Museologia, Patrimônio Cultural do Instituto de Artes da Universidade Federal do Rio Grande do Sul (UFRGS) criado em 2002, o Curso de Especialização em Museologia da Universidade Federal de Goiás (UFG) em 2002, o Curso de Especialização em Museologia do Centro Universitário Franciscano de Santa Maria no Rio Grande do Sul e o Curso de Especialização em Museologia da Universidade do Estado de Santa Catarina (UDESC), ambos criados em 2003, e o Curso de Especialização em Museologia da Escola de Música e Belas Artes do Paraná (EMBAP) 
criado em 2004. Acrescentam-se, o Curso de Especialização em Museologia da Universidade Federal do Amazonas (UFAM) e o Curso de Especialização em Museologia da Universidade Federal de Ouro Preto (UFOP) em Minas Gerais, criado em 2012. Para além destes, assinala-se a realização do Curso de Estudos Avançados em Museologia (CEAM), fruto da parceria firmada entre a Associação Brasileira de Museus (ABM) e a Universidade Lusófona de Humanidades e Tecnologias de Lisboa (ULHT), Portugal.

Após discorrer sobre as iniciativas de cursos de especialização, retoma-se a trajetória da formação graduada em Museologia, a qual a partir do ano de 2003 foi marcada por significativa mudança em termos quantitativos de oferta no Brasil. A formação graduada em Museologia, antes com apenas dois cursos de graduação - com funcionamento no Rio de Janeiro (UNIRIO) e na Bahia (UFBA) - passou a contar com 17 cursos $^{13}$, presentes em todas as regiões do país. No Quadro 1descrevem-se os cursos em funcionamento no Brasil apontando a região, o estado, a instituição e o ano de criação do curso:

Quadro 1: Instituições de Ensino Superior com cursos de graduação em Museologia

\begin{tabular}{|c|c|c|c|c|}
\hline REGIÃO & ESTADO & NOME DA INSTITUIÇÃO & SIGLA & $\begin{array}{c}\text { ANO DE } \\
\text { CRIAÇÃO }\end{array}$ \\
\hline \multirow[t]{5}{*}{ Sul } & \multirow{2}{*}{$\begin{array}{c}\text { Santa } \\
\text { Catarina }\end{array}$} & Universidade Federal de Santa Catarina & UFSC & 2010 \\
\hline & & Centro Universitário Barriga Verde & UNIBAVE* & 2004 \\
\hline & \multirow[t]{2}{*}{$\begin{array}{l}\text { Rio Grande } \\
\text { do Sul }\end{array}$} & $\begin{array}{l}\text { Universidade Federal do Rio Grande do } \\
\text { Sul }\end{array}$ & UFRGS & 2008 \\
\hline & & Universidade Federal de Pelotas & UFPEL & 2006 \\
\hline & Paraná & Univers idade Estadual do Paraná & UNESPAR & 2018 \\
\hline \multirow[t]{4}{*}{ Sudeste } & \multirow[t]{2}{*}{ São Paulo } & Univers idade Camilo Castelo Branco & UNICASTELO* & 2014 \\
\hline & & $\begin{array}{l}\text { Faculdade de Educação, Ciências e } \\
\text { Artes Dom Bosco de Monte Aprazível }\end{array}$ & $\begin{array}{l}\text { FAECA DOM } \\
\text { BOSCO* }\end{array}$ & 2011 \\
\hline & $\begin{array}{l}\text { Rio de } \\
\text { Janeiro }\end{array}$ & $\begin{array}{l}\text { Universidade Federal do Estado do Rio } \\
\text { de Janeiro }\end{array}$ & UNIRIO & 1979 \\
\hline & Minas & Universidade Federal de Ouro Preto & UFOP & 2008 \\
\hline
\end{tabular}

${ }^{13}$ De acordo com dados do e-MEC, identificam-se três cursos em Museologia na modalidade a distância, sendo que destes apenas um consta como iniciado em 13 de março de 2019. Os cursos desta modalidade não foram contemplados neste relato. Disponível em: http://emec.mec.gov.br/ 


\begin{tabular}{|c|c|c|c|c|}
\hline \multirow{2}{*}{$\begin{array}{c}\text { Centro- } \\
\text { Oes te }\end{array}$} & $\begin{array}{c}\text { Gerais } \\
\text { Dedstrito }\end{array}$ & Universidade Federal de Minas Gerais & UFMG & 2010 \\
\cline { 2 - 5 } & Goiás & Universidade de Brasília & UnB & 2009 \\
\hline Norte & Pará & Univers idade Federal do Pará & UFPA & 2010 \\
\hline Nordeste & Bahia & Universidade Federal da Bahia & UFBA & 1970 \\
\cline { 3 - 5 } & & Universidade Federal do Recôncavo da & UFRB & 2006 \\
\hline & Sergipe & Universidade Federal de Sergipe & UFS & 2007 \\
\hline & Pernambuco & Universidade Federal de Pernambuco & UFPE & 2009 \\
\hline
\end{tabular}

Fonte: e-MEC (2017) consulta atualizada em 2020

Nota: instituições privadas marcadas com *

A maioria dos cursos de graduação em Museologia é ofertado por instituições de ensino superior públicas. Apenas três cursos são ofertados por instituições privadas. Estes cursos funcionam vinculados a departamentos, faculdades ou institutos de História, Belas Artes, Antropologia, Ciência da Informação ou Arquitetura, o que revela que o ensino em Museologia apresenta dispersão de sua vinculação às áreas científicas (ARAÚJO; MARQUES; VANZ, 2011).

O panorama dos cursos de graduação em Museologia reflete que "o século XXI assistiu a um crescimento significativo do campo da Museologia no Brasil" (SOPHIA; LOUREIRO, 2012, p. 129). Este fenômeno encontra aporte nas ações do Instituto Brasileiro de Museus (IBRAM) em associação a uma conjuntura favorável de instituições de ensino superior e articulações políticas, apoiada pelo programa do governo federal designado Reestruturação e Expansão das Universidades Federais (REUNI). No entanto, cumpre destacar que o último curso de graduação em Museologia foi criado há dois anos, no caso o curso da UNESPAR ${ }^{14}$.

A pós-graduação stricto sensu em Museologia no Brasil, por sua vez, despontou em 2006 com a criação do curso de mestrado pelo Programa de Pós-Graduação em Museologia e Patrimônio (PPG-PMUS) a partir da parceria entre a UNIRIO e o MAST. Cinco anos após a criação do mestrado, deu-se a criação do curso de doutorado em 2011, que se mantém como o único neste nível no país. Inclusive, mantém-se como o único na América Latina até o presente momento. Nos anos sequentes, houve a criação de cinco cursos de mestrado no país, sendo quatro cursos

\footnotetext{
${ }^{14}$ Ver http://www.unespar.edu.br/noticias/unespar-ofertara-primeiro-bacharelado-em$\underline{\text { museologia-do-estado }}$
} 
de mestrado acadêmico e dois mestrados profissionais. No Quadro 2, descrevem-se os cursos de pós-graduação stricto sensu em Museologia apontando a região, o estado, a instituição, o programa de pósgraduação, o ano de criação e o nível do curso:

Quadro 2: Cursos de Pós-Graduação Stricto Sensu em Museologia no Brasil

\begin{tabular}{|c|c|c|c|c|c|}
\hline REGIÃO & ESTADO & NOME DA INSTITUIÇÃO & PROGRAMA & $\begin{array}{c}\text { ANO DE } \\
\text { CRIAÇÃO }\end{array}$ & M/MP/D \\
\hline \multirow[t]{4}{*}{ Sudeste } & \multirow[t]{3}{*}{$\begin{array}{l}\text { Rio de } \\
\text { Janeiro }\end{array}$} & \multirow{2}{*}{$\begin{array}{c}\text { Universidade Federal do } \\
\text { Estado do Rio de Janeiro } \\
\text { (UNIRIO) e Museu de } \\
\text { Astronomia e Ciências Afins } \\
\text { (MAST) }\end{array}$} & \multirow[t]{2}{*}{$\begin{array}{l}\text { Museologia e } \\
\text { Patrimônio }\end{array}$} & 2006 & M \\
\hline & & & & 2011 & $\mathrm{D}$ \\
\hline & & $\begin{array}{l}\text { Museu de Astronomia e } \\
\text { Ciências Afins (MAST) }\end{array}$ & $\begin{array}{c}\text { Preservação de } \\
\text { Acervos de } \\
\text { Ciência e } \\
\text { Tecnologia }\end{array}$ & 2014 & MP \\
\hline & São Paulo & $\begin{array}{l}\text { Universidade de São Paulo } \\
\text { (USP) }\end{array}$ & Museologia & 2012 & M \\
\hline \multirow[t]{2}{*}{ Nordeste } & Bahia & $\begin{array}{l}\text { Universidade Federal da Bahia } \\
\text { (UFBA) }\end{array}$ & Museologia & 2013 & M \\
\hline & Piauí & $\begin{array}{l}\text { Universidade Federal do Piauí } \\
\text { (UFPI) }\end{array}$ & $\begin{array}{l}\text { Arte, Patrimônio } \\
\text { e Museologia }\end{array}$ & 2014 & MP \\
\hline Sul & $\begin{array}{c}\text { Rio } \\
\text { Grande } \\
\text { do Sul }\end{array}$ & $\begin{array}{l}\text { Universidade Federal do Rio } \\
\text { Grande do Sul (UFRGS) }\end{array}$ & $\begin{array}{l}\text { Museologia e } \\
\text { Patrimônio }\end{array}$ & 2016 & M \\
\hline
\end{tabular}

Fonte: Autoria própria a partir dos dados da Plataforma Sucupira (2019)

Nota: $M=$ Mestrado Acadêmico; $M P=$ Mestrado Profissional; e $D=$ Doutorado

A partir dos dados condensados no Quadro 2, observa-se que os cursos de pós-graduação stricto sensu em Museologia se concentram atualmente em três das cinco regiões do país: Sudeste (nos estados do Rio de Janeiro e São Paulo); Nordeste (nos estados da Bahia e Piauí); e Sul (no estado do Rio Grande do Sul).

\section{Reflexões finais}

O presente relato abordou a institucionalização e a configuração atual da formação em Museologia no Brasil, tendo como ponto de partida sua origem em 1932 até seu estado atual neste século XXI.

A institucionalização da formação em Museologia no Brasil foi marcada pelo pioneirismo do país na década de 1930 e por significativo 
avanço, especialmente nos primeiros anos do século XXI, acompanhando o movimento internacional do mundo dos museus e a demanda por formação, contribuindo para a consolidação da teoria e da prática, bem como para a qualificação de alto nível.

O alargamento da oferta de formação em Museologia no Brasil já era uma necessidade evidenciada desde os anos 1980, no entanto, só após duas décadas a necessidade de formação e capacitação de recursos humanos na área ganhou força, quando oficialmente passou a compor um dos eixos programáticos de uma estratégia do governo federal do Brasil: a Política Nacional de Museus (PNM). Para além disso, reforçam-se as iniciativas do IBRAM e o programa REUNI, bem como se atribui, também, as investigações e agendas no escopo da área devidamente desenvolvidas em outras áreas de conhecimento, como Educação, Antropologia, História, Ciência da Informação, dentre outras, o que denota as intercessões necessárias.

Em termos de designação na formação graduada apresenta homogeneidade em sua nomenclatura. No que toca a oferta pósgraduada, percebe-se ínfima heterogeneidade. Evidencia-se, ainda, há uma discrepância entre a quantidade de cursos de graduação presentes em todas as regiões do país e a quantidade de cursos de pós-graduação stricto sensu com oferta em três das cinco regiões do país. Este cenário é revelador da necessidade de equilíbrio formativo neste nível.

Os resultados aqui descritos delineiam o percurso histórico e o estágio atual da oferta formativa em Museologia, esperando que o conhecimento do estágio formativo da área contribua para o estabelecimento de estratégias e promoção de parcerias entre as instituições e os pesquisadores da área da Museologia em atuação na graduação e na pós-graduação.

Ante o exposto, em termos de continuidade deste relato, registra-se que a autora pretende dar continuidade à pesquisa pela análise do currículo dos Cursos de Graduação em Museologia com vistas a identificar os conteúdos contemplados, bem como as fontes e autores constantes da Bibliografia básica e complementar das disciplinas, refletindo, assim, sobre a formação do Museólogo. E, em sequência, partir-se-á para o currículo dos programas de pós-graduação, lóci privilegiados de práticas científicas, produção de conhecimento e formação de pesquisadores.

\section{Referências}

ABREU, Regina. O paradigma evolucionista e o Museu Histórico Nacional. Anais do Museu Histórico Nacional, v. 27, n. 1, p. 7-19, 1995.

ARAÚJO,Carlos Alberto Ávila; MARQUES, Angélica Alves da Cunha; VANZ, Samille Andréa Souza. Arquivologia, Biblioteconomia e Museologia 
integradas na Ciência da Informação: as experiências da UFMG, da UnB e da UFRGS. Ponto de Acesso, v. 5, n. 1, p. 85-108, 2011.

BARROSO, Gustavo. O Curso de Museus. Anais do Museu Histórico Nacional, v. 5, p. 191-200, 1944.

BARROSO, Gustavo.Introdução à técnica de museus:parte geral e parte básica. Rio de Janeiro: Gráfica Olímpica, 1946. Vol. I.

BRASIL. Decreto-lei no 16.078, de 13 de julho de 1944. Disponível em: http://www2.camara.leg.br/legin/fed/decret/1940-1949/decreto-1607813-julho-1944-461459-publicacaooriginal-1-pe.html. Acesso em: 30 maio 2017.

BRASIL. Ministério da Educação. Sistema e-MEC. Cursos de Graduação em Museologia. 2017. Disponível em: http://emec.mec.gov.br/.

BRASIL. Ministério da Educação. Sistema e-MEC. Cursos de Graduação em Museologia. 2020. Disponível em: http://emec.mec.gov.br/.

BRIGOLA, João Carlos Pires. O actual ensino universitário da Museologia: uma reflexão crítica e uma proposta. Museologia.pt, v.3, p. 13-18, 2009.

BRULON-SOARES, Bruno César; CARVALHO, Luciana Menezes de; CRUZ, Henrique de Vasconcelos. O nascimento da Museologia: confluências e tendências do campo museológico no Brasil. In: MAGALHÃES, Aline Montenegro; BEZERRA, Rafael Zamorano. 90 anos do Museu Histórico Nacional em debate (1922-2012). Rio de Janeiro: Museu Histórico Nacional, 2014, p. 242-260. Disponível em:

https://www.academia.edu/8889489/O_nascimento_da_Museologia_confl u\%C3\%AAncias_e_tend\%C3\%AAncias_do_campo_museol\%C3\%B3gico_n o_Brasil?auto=download.

BRUNO, Maria Cristina Oliveira. Um ponto de vista sobre os cenários e articulações para formação profissional em Museologia: conquistas e perspectivas no Brasil. In: MORENO, Luís Gerardo Morales (Ed.). Tendencias de la Museología Latina: articulaciones, horizontes, diseminaciones. Ciudad de México: Instituto Nacional de Antropología e Historia, 2015, p. 104-108.

COELHO, Priscilla Arigoni. Metáforas em rede no processo de institucionalização:um estudo sobre memória e discurso da Museologia no Brasil (1932 a 1985). Tese (Doutorado em Memória Social). Universidade Federal do Estado do Rio de Janeiro, Rio de Janeiro, 2015.

COSTA, Luciana Ferreira da. Museologia no Brasil, século XXI: atores, instituições, produção científica e estratégias. 2017. Tese (Doutoramento 
em História e Filosofia da Ciência) - Universidade de Évora, Évora, Portugal. Disponível em:

https://dspace.uevora.pt/rdpc/bitstream/10174/21966/1/Doutoramento\% 20-

\%20Hist\%C3\%B3ria\%20e\%20Filosofia\%20da\%20Ci\%C3\%AAncia\%20\%20Museologia\%20-\%20Luciana\%20Ferreira\%20da\%20Costa.pdf

COSTA, Heloísa Helena. Formação em Museologia - o caso da Bahia. Anais do Museu Histórico Nacional, v. 41, p. 239-253, 2009.

DUARTE CÂNDIDO, Manuelina Maria. Relações Brasil-Portugal na Museologia contemporânea. In: COLÓQUIO DO PPRLB (PÓLO DE PESQUISA SOBRE RELAÇÕES LUSO-BRASILEIRAS) - PORTUGAL NO BRASIL, PONTES PARA O PRESENTE, 6., 2013, Rio de Janeiro. Atas... Rio de Janeiro: Real Gabinete Português de Leitura, 2013.

DUARTE CÂNDIDO, Manuelina Maria; RUOSO, Carolina. (2012). Museologia no Brasil e em Portugal: alguns atores e ideias em circulação. Anais do Museu Histórico Nacional, v. 44, p. 33-52, 2012.

HERNÁNDEZ-HERNÁNDEZ, Francisca. Planteamientos teóricos de la museología. Gijón: Trea, 2006.

KNAUSS, Paulo. A presença de estudantes: o encontro de museus e a escola no Brasil a partir da década de 50 do século XX. Varia História, v. 27, n. 46, p. 581-597, 2011.

MAROEVIĆ, IVo. Introduction to museology: the European approach. München: Verlag Dr. Christian Müeller-Straten, 1998.

PLATAFORMA SUCUPIRA.Cursos avaliados e reconhecidos. Área Comunicação e Informação. Área Museologia. 2018. Disponível em: https://sucupira.capes.gov.br/sucupira/public/consultas/coleta/programa/ quantitativos/quantitativoAreaConhecimento.jsf?areaAvaliacao=31 Acesso em: 03 maio 2018.

POULOT, Dominique. Museus e Museologia.Belo Horizonte: Autêntica, 2013.

RANGEL, Marcio Ferreira. Museologia e patrimônio: encontros e desencontros. Boletim do Museu Paraense Emílio Goeldi Ciências Humanas, v. 7, n. 1, p. 103-112, 2012.

RÚSSIO, Waldisa. Formação do museólogo: por que em nível de pósgraduação? In: BRUNO, Maria Cristina Oliveira. Waldisa Rússio Camargo Guarnieri: textos e contextos de uma trajetória profissional. São Paulo: 
Pinacoteca do Estado, Secretaria de Estado da Cultura; Comitê Brasileiro do Conselho Internacional de Museus, 2010.

SÁ, Ivan Coelho de. Matrizes do pensamento museológico de Gustavo Barroso. Rio de Janeiro: Interciência, 2019.

SÁ, Ivan Coelho de. História e memória do curso de Museologia: do MHN à Unirio. Anais do Museu Histórico Nacional, v. 39, p. 10-42, 2007.

SÁ, Ivan Coelho de. As matrizes francesas e origens comuns no Brasil dos cursos de formação em Arquivologia, Biblioteconomia e Museologia.

Acervo, v. 26, n. 2, p. 31-35, 2013.

SÁ, Ivan Coelho de. Institucionalização das práticas museológicas: oitenta anos do Curso de Museus. In: MAGALHÃES, Aline Montenegro; BEZERRA, Rafael Zamorano. 90 anos do Museu Histórico Nacional em debate (19222012). Rio de Janeiro: Museu Histórico Nacional, 2014, p. 242-260.

SÁ, Ivan Coelho de; SIQUEIRA, Graciele Karine. Curso de Museus - MHN, 1932-1978: alunos, graduandos e atuação profissional. Rio de Janeiro: UNIRIO, 2007.

SANTOS, Maria Célia Teixeira Moura. Encontros museológicos: reflexões sobre a Museologia, educação e o museu. Rio de Janeiro: MinC/IPHAN/DEMU, 2008.

SCHEINER, Tereza Cristina Moletta. Cultura material e Museologia: considerações. In: GRANATO, Marcus (Org.). Museologia e patrimônio. Rio de Janeiro: Museu de Astronomia e Ciências Afins, 2015, p. 17-48.

SILVA, Regina Cláudia Oliveira da. A ação educacional e o legado cultural de Gustavo Barroso para a moderna Museologia brasileira. Tese (Doutorado em Educação Brasileira). Universidade do Ceará, Fortaleza, 2014.

SIQUEIRA, Graciele Karine. Curso de Museus - MHN, 1932-1978: o perfil acadêmico-profissional. Dissertação (Mestrado em Museologia e Patrimônio). Universidade Federal do Estado do Rio de Janeiro e Museu de Astronomia e Ciências Afins, Rio de Janeiro, 2009.

SOPHIA, Daniela Carvalho; LOUREIRO, Maria Lúcia de Niemeyer Matheus. A produção científica da área de museologia no Portal de Periódicos da Capes. Museologia e Patrimônio, v. 5, n. 1, p. 125-141, 2012.

TANUS, Gabrielle Francinne de Souza Carvalho. Cenário acadêmicoinstitucional dos cursos de Arquivologia, Biblioteconomia e Museologia do 
Brasil. Dissertação (Mestrado em Ciência da Informação). Universidade Federal de Minas Gerais, Belo Horizonte, 2013.

WILLIAMS, Daryle. Sobre patronos, heróis e visitantes: o Museu Nacional, 1930-1960. Anais do Museu Histórico Nacional, v. 29, p. 141-186, 1997. 